J. Lake Sci. (湖泊科学) , 2020, 32(6): 1837-1847

DOI 10. 18307/2020. 0623

(c) 2020 by Journal of Lake Sciences

\title{
黄河下游游荡段不同畸形河湾的演变特点
}

\author{
江青蓉, 夏军强**, 周美蓉, 王英珍 \\ (武汉大学水资源与水电工程国家重点实验室, 武汉 430072)
}

\begin{abstract}
摘 要: 1980s 中期以来, 黄河下游游荡段经常出现畸形河湾, 分析其演变过程及特点对游荡段治理具有重要意义. 本研 究采用黄河下游游荡段的遥感影像和实测断面地形资料,描述了不同畸形河湾的演变过程并分析其河湾形态参数和断 面形态的变化. 研究表明,黄河下游游荡段的畸形河湾具有演变周期短、扭曲程度较大和易发生自然裁弯等特点. 游荡段 不同位置畸形河湾的演变特点不同: 游荡段上段的畸形河湾演变缓慢,裁弯历时长; 中段的畸形河湾演变速率较高, 河湾 扭曲程度大; 下段的畸形河湾演变速率高, 容易发生自然裁弯. 河湾形态参数可反映畸形河湾的演变过程, 其变化特点与 畸形河湾的形成和裁弯过程相对应. 在畸形河湾形成过程中, 曲率半径和河湾间距减小, 弯曲度、水流夹角和河湾振幅增 大. 游荡段 3 个畸形河湾弯曲度的最大值分别为 $1.20 、 2.10$ 和 1.61 , 反映了不同畸形河湾的扭曲程度. “ $\Omega$ ” 形畸形河湾裁 弯后的曲率半径、水流夹角、河湾振幅和河湾间距约为其演变过程中最值的 $605 \% 、 59 \% 、 27 \%$ 和 133\%. “ M” 形畸形河湾裁 弯后水流夹角、河湾振幅和河湾间距约为其最值的 $37 \%$ 、 $83 \%$ 和 $152 \%$. 在畸形河湾形成时期,伊洛河口断面位于畸形河 湾凹岸侧的滩地以 $94 \mathrm{~m} / \mathrm{a}$ 的速率崩塌. 裁弯后, 河槽冲刷, 两岸滩地崩退, 河槽展宽速率为 $148 \mathrm{~m} / \mathrm{a}$. 河床底部的冲刷从 深泓点逐渐向两边发展.
\end{abstract}

关键词: 畸形河湾;演变过程;平面形态;黄河下游;游荡段;遥感影像

\section{Evolution process of different abnormal river bends in the braided reach of the Lower Yellow River*}

JIANG Qingrong, XIA Junqiang** , ZHOU Meirong \& WANG Yingzhen

( State Key Laboratory of Water Resources and Hydropower Engineering Science, Wuhan University, Wuhan 430072, P.R.China)

\begin{abstract}
Since the mid-1980s, the braided channel reach of the Lower Yellow River has formed some abnormal river bends. Analysis of the evolution processes and characteristics of abnormal river bends are of great significance for the regulation of the braided reach. Based on the remote sensing imagery and the cross-sectional topography, this study describes the evolution processes of abnormal river bends and variation of morphological characteristic parameters. The result shows that the abnormal river bends in braided channel reach of the Lower Yellow River have the characteristics of short evolution duration, high distortion level and prone to natural cutoff and the bends in different location have different evolution characteristics. The first bend in the upper braided reach evolves slowly and the cut-off period is long. The second bend in the middle braided reach evolves rapidly and highly distorted. The third bend in the lower braided reach evolves rapidly and is prone to generate natural cutoff. Variation of river bend morphology reflects the evolution process of three abnormal river bends, which are corresponding to the bend formation and cutoff processes. The formation of the abnormal river bend is a process in which the curvature radius and river bend spacing decreases, and the bend curvature radius, angle of water flow and bend amplitude increase. The maximum curvature radius of the three bends in the braided reach are $1.20,2.10$ and 1.61 , respectively, reflecting the distortion degree of different bends. After cut-off, the curvature radius, angle of water flow, bend amplitude and river bend spacing are about $605 \%, 59 \%, 27 \%$, and $133 \%$ of the extreme value during the evolution of the " $\Omega$ " shape river bend. For “M" shape river bend, angle of water flow, bend amplitude and river bend spacing after cutting are about $37 \%, 83 \%$, and $152 \%$ of their extreme values. The cross-sectional profile at the Yiluo River outlet reflected that the beach on the concave bank of the river bend continuously collapsed at a rate of about $94 \mathrm{~m} /$ a during the formation period of
\end{abstract}

* 2019-08-30 收稿;2019-12-12 收修改稿.

国家自然科学基金项目 (51725902, 51579186) 和国家重点基础研发计划项目 (2017YFC0405501) 联合资助.

** 通信作者;E-mail: xiajq@ whu.edu.cn. 
abnormal river banks. The cut-off has a great influence on the cross-sectional profile. After cut-off, the beaches on both bank collapsed, and the river channel widen at a rate of $148 \mathrm{~m} / \mathrm{a}$. The erosion at the riverbed developed from the deep point to its two sides. Keywords: Abnormal river bends; evolution processes; bend morphology; Lower Yellow River; braided reach; remote sensing images

20 世纪 80 年代中期以来,黄河下游的水沙条件发生了较大变化, 河道不断萎缩, 河床调整在平面形态 上经常发育畸形河湾 ${ }^{[1-3]}$. 畸形河湾是河道为适应水沙条件的改变, 在节点限制的情况下, 局部冲积内的整 个河湾形态发生扭曲的一种过度弯曲的河湾形态 ${ }^{[4]}$. 畸形河湾在演变后期常呈 “ $\Omega$ ”形、“ $S$ ” 形、“ $Z$ ”形和 “M”形,并常伴随着裁弯现象发生. 自然裁弯是畸形河湾演变的终点, 同时也是引起河势变化的突发事 件 ${ }^{[5]}$. 根据河湾平面形态和发生位置, 自然裁弯主要可分为颈口裁弯和斜槽裁弯. 畸形河湾给黄河下游的防 洪安全和滩区治理带来了严重威胁 ${ }^{[6-7]}$, 特别是在孟津至高村的游荡型河段, 畸形河湾的频繁形成导致整治 工程脱流或半脱流现象增多,加剧了局部河段的游荡程度与治理难度. 因此,研究黄河下游游荡段畸形河湾 的演变过程及相关形态特征参数的变化, 不仅有助于掌握黄河下游游荡段畸形河湾的演变规律, 也能为游 荡段的治理提供科学依据.

近年来不少学者研究了黄河畸形河湾的演变特点. 胡一三 ${ }^{[6]}$ 结合黄河下游的河势演变资料,利用河势 图描述了游荡段及过渡段内的畸形河湾,并阐述了畸形河湾演变对黄河下游防洪安全的不利影响. 孙赞盈 等 ${ }^{[8]}$ 研究表明: 畸形河湾是短期内局部河段行洪能力降低的重要原因,利用人工裁弯等方法能有效消除畸 形河湾并提高河道行洪能力. 张林忠等 ${ }^{[9]}$ 利用黄河下游实测资料和模型试验成果, 分析了黄河下游畸形河 湾的特点, 指出畸形河湾是黄河下游特定水沙条件和河道边界条件共同作用的结果, 具有特定的演变过程、 持续时间相差较大等特点. 李志威等 ${ }^{[10-11]}$ 结合遥感影像图, 分析了河湾的发育过程与裁弯模式, 并分析了塔 里木河的自然裁弯现象及其成因, 表明发生塔里木河发生自然裁弯的主要原因是边界条件变化, 同时来水 来沙条件也是重要影响因素. 以往对于黄河下游畸形河湾演变过程的研究较少, 且主要采用主溜线图来描 述畸形河湾的变化过程, 但主溜线图空间精度较低, 只能粗略反映水流流路的变化. 因此, 有必要采用精度 更高的多源数据来描述畸形河湾的演变过程.

本研究以黄河下游游荡段的遥感影像资料和实测断面地形资料为基础, 选取游荡段 3 个典型畸形河湾 为研究对象, 分析其演变过程并对河湾形态参数和断面形态的变化进行计算, 从而得到典型畸形河湾的演 变特点.

\section{1 研究河段和研究方法}

\section{1 游荡段概况}

黄河下游根据河道特性的不同, 可分为游荡段、过渡段和弯曲段 (图 1). 相较于过渡段和弯曲段, 黄河 下游游荡段水流散乱, 主流摆动频繁, 是当前众多学者研究的重点.

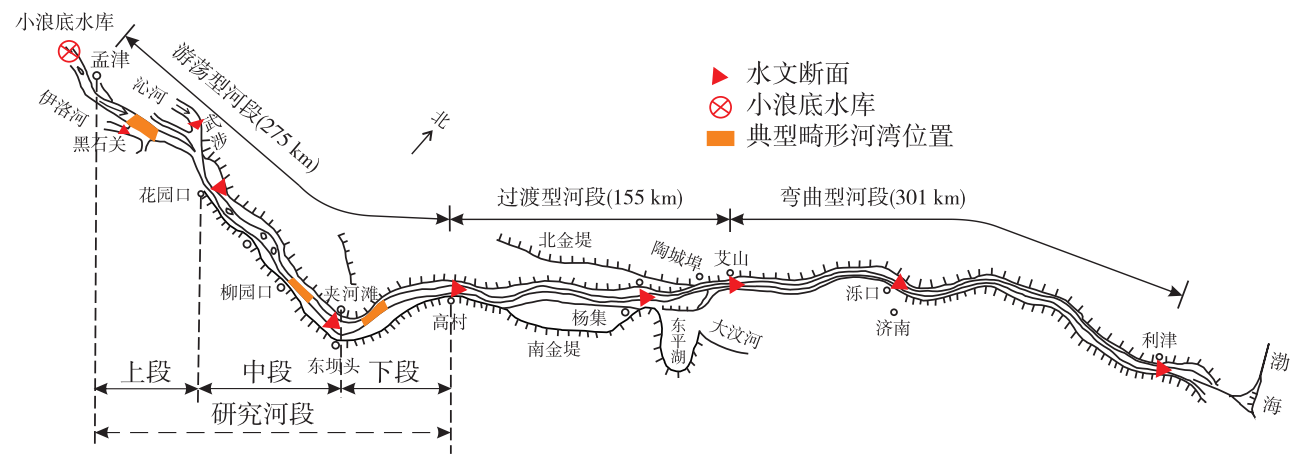

图 1 黄河下游河道平面示意

Fig.1 Sketch of the Lower Yellow River (LYR) 
孟津一高村河段是典型的游荡型河段, 主槽一般宽达 $1.5 \sim 3.5 \mathrm{~km}$, 有时超过 $4.0 \mathrm{~km}$; 断面形态较为宽浅, 平滩流量下的河相系数值在 20 40 之间变化. 河床纵比降较过渡段和弯曲段大,约在 1.72\% 000 2.65\% 之间. 滩槽高差小, 多在 $2 \mathrm{~m}$ 以下, 河身顺直, 弯曲系数一般小于 $1.3^{[12-13]}$. 河道内沙洲密布, 水流散乱多汊, 一般为 $1 \sim 3$ 股,有时多达 4 5 股, 河势多变 ${ }^{[14-15]}$.

不同河段的水文情势、河床组成、河道整治工程情况和比降不同,所形成的畸形河湾也具有不同的特点. 因此, 综合水文站布置等因素, 本研究将游荡段分为 3 个小河段进行研究, 即孟津一花园口河段 (上段), 花园 口一夹河滩河段 (中段), 夹河滩一高村河段(下段), 其位置如图 1 所示.

\section{2 水沙条件}

图 2 描述了 1970-2016 年黄河下游水沙的变化情况. 1986-1999 年, 年均水量和沙量出现大幅度减少 现象, 特别是水量, 减少幅度达 $30 \%$; 在小浪底水库运行后, 进人黄河下游的水量小幅度增加, 但总量依旧偏 少, 而来沙量急剧减少, 较水库运行前减少约 $92 \%$. 总的来说, $1980 \mathrm{~s}$ 中期以来, 黄河下游的水沙变化大, 黄河 下游进人小水少沙时期.

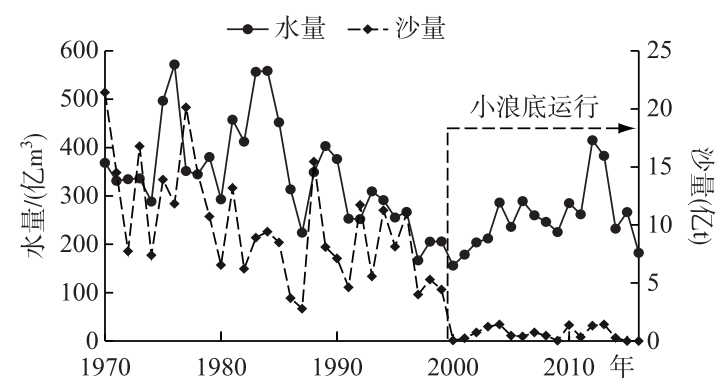

图 2 1970－2016 年黄河下游年均水沙变化

Fig. 2 Annual runoff and sediment load in the Lower Yellow River during 1970-2016

\section{3 研究方法}

结合黄河下游游荡段的河势图、Landsat 遥感影像和 Google Earth 软件,统计了 1975-2016 年黄河下游 游荡段形成的畸形河湾, 结果见图 3. 图中每一条线段都表示一个畸形河湾从形成到裁弯的过程. 1980s 中 期以来, 游荡段形成的畸形河湾较多, 特别是在游荡段中段, 而近年来畸形河湾主要集中在游荡段上段. 对 于游荡段的上、中和下 3 个河段,分别选取 2006-2012 年巩义神堤一英峪畸形河湾、2002-2006 年柳园口一 古城畸形河湾和 1992-1997 年王夹堤一王高寨畸形河湾 (图 3 中虚线线段) 作为其典型畸形河湾并进行分 析, 其相对位置如图 1 和图 3 所示.

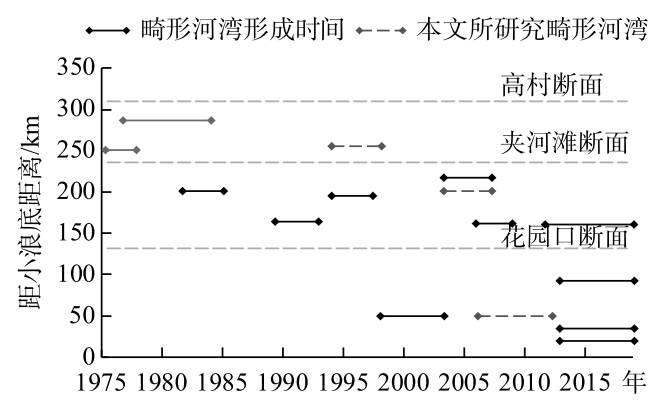

图 3 1975-2016 年游荡段畸形河湾形成时间

Fig.3 Formation period of abnormal river bends in the braided reach during 1975-2016

(1) 河槽位置的确定方法

为研究畸形河湾的演变过程, 需要对不同时期河槽的位置进行确定, 但河道形态易受外界因素干扰, 使 
用常规监测方法 (如河势图法、主溜线法) 无法对其进行全面准确的描述 ${ }^{[16]}$. 遥感是在非接触、远距离的情 况下获取目标信息的方法 ${ }^{[17-18]}$, 具有信息实时、准确、直观的特点 ${ }^{[19]}$. 遥感技术通过分析地球表面反射不同 波段电磁波的特性,从高空中获取地球表面陆地和水体信息 ${ }^{[20]}$,并对所获取的信息进行整理、提取、比较、处 理分析, 从而得到目标及其环境的位置、状态等信息特征 ${ }^{[10]}$. 本研究中采用美国航天局提供的 Landsat 系列 遥感数据, 该数据具有时间序列长 (1972 年至今)、分辨率适中、连续性好、覆盖范围广、可直接从互联网上 下载等特点, 是目前遥感领域重要的数据来源.

本研究所采用的遥感资料来源于中国科学院的 “地理空间数据云”网站 (https://www. gscloud.cn/) 和 美国地质调查局 (USGS) 的“GloVis”网站 (https://glovis.usgs.gov/). 该数据库中遥感影像资料较多且影像 时间差异大, 因此需要挑选出最具有代表性且云量较少的遥感影像. 由于汛期水量大, 洪水漫滩后滩槽难以 区分, 且畸形河湾的演变受汗期影响较大, 故对于每一个典型畸形河湾,下载畸形河湾演变时期具有代表性 的汛前及汛后遥感影像. 根据遥感影像上水陆颜色差异和河道特征等直接采用人工解译的方法 ${ }^{[21]}$, 并结合 Google Earth 软件,综合分析图像特征和水系特征,识别河槽的相对位置(图 4).

对遥感影像的具体处理步骤如下: (1) 使用 ENVI 5.1 软件中的 “Layer Stacking” 和“Stretch”功能对遥感 影像进行合成和拉伸, 其中选取合成的 3 个波段为近红外、中红外及红波段, 合成的遥感影像为非标准假彩 色图像, 突出水陆边界, 便于目视识别; (2) 结合 Google Earth 软件和河势演变资料, 在遥感影像上裁剪研究 河段范围; (3) 结合黄河下游游荡段的淤积断面、河道整治工程分布资料和遥感影像上不同地貌的颜色差 异, 利用 ENVI 5.1 软件的 “ROI” 功能绘制出水陆边界线、断面位置及河道工程位置并保存; (4) 将绘制好的 水陆边界线、断面及工程位置导人到 ArcMap 软件中, 在软件界面上可直观识别畸形河湾的演变过程, 对图 像进行处理,可获得不同时期典型畸形河湾的河槽位置图 (图 5、6、7).

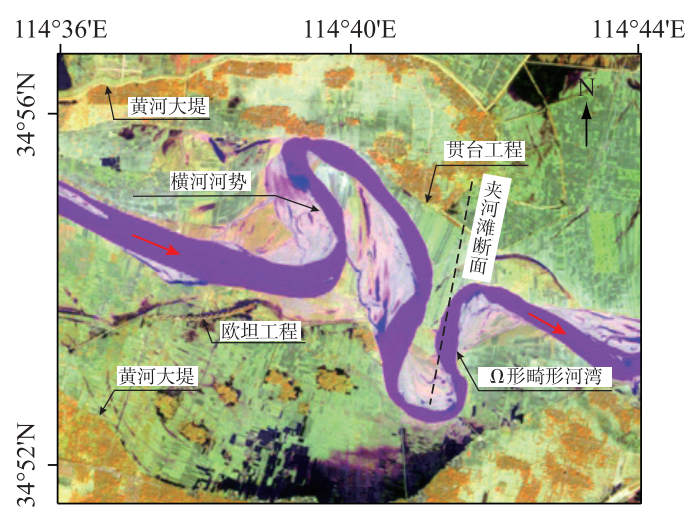

图 42005 年夹河滩断面附近的局部遥感影像

Fig.4 Remote sensing image near Jiahetan section in 2005

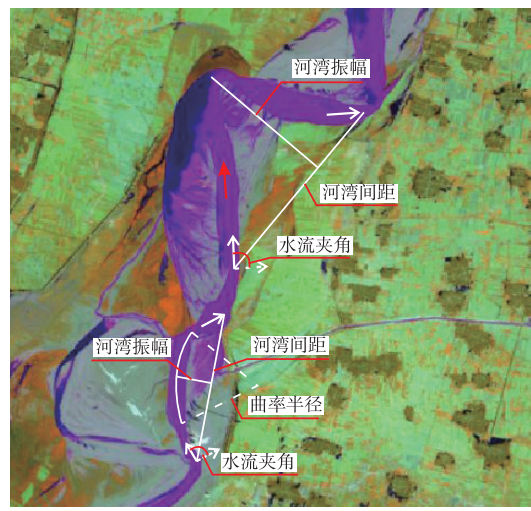

图 5 畸形河湾的河湾形态参数示意

Fig.5 Sketch of morphological parameters of river bend in an abnormal river bend

\section{(2) 河湾形态参数的计算}

弯道的形成与演变是描述畸形河湾演变过程的一个直观因素形态参数, 弯道的弯曲度越大, 所形成的 畸形河湾越扭曲, 水流流态也更加复杂. 规则弯曲型河流的平面形态可以用一系列方向相反的弯道和介于 其间的过渡段衔接而成, 其特征可用河湾平面形态参数来衡量, 包括曲率半径 $R$ 、中心角 $\psi$ 、直河段长 $l$ 、河湾 间距 $T$ 、设计河宽 $B$ 、弯曲振幅 $P$ 及河湾跨度 $L$ 等 ${ }^{[22]}$. 由于畸形河湾扭曲严重, 此处仅研究曲率半径 $R$ 、水流 夹角 $a$ 、弯曲振幅 $P$ 和河湾间距 $T$ 在畸形河湾演变过程中的变化, 其物理意义如图 5 所示, 其中, 水流夹角 $a$ 指水流在畸形河湾进出口所成的夹角.

在畸形河湾演变过程中, 水流在短距离内蜿蜒前进, 形成扭曲的河湾, 延长河道长度, 因此本研究引进 无量纲系数弯曲度来综合考虑畸形河湾河道中心线和水流直线距离的变化. 本研究中弯曲度的定义为两个 
固定断面间的河道中心线的长度 $\mathrm{S}_{2}$ 与水流直线距离 $\mathrm{S}_{1}$ 的比值(图 6、7、8), 可反映不同河湾的弯曲程度.

\section{2 游荡段不同位置畸形河湾的演变过程}

\section{1 巩义神堤一英峪畸形河湾的演变过程}

2006- 2012 年,在巩义神堤一英峪河段之间形成了一个大 “ $\Omega$ ”形畸形河湾,并在水流的作用下于 2008 年汛期发生斜槽裁弯, 最终消亡. 神堤控导工程位于伊洛河人黄河口以上, 此河段修建的河道整治工程较 少,河势变化大. 自 1997-2002 年形成畸形河湾后,此河段常年存在“S”形弯道(图 6a). 在 2007 年汛后, 原 有的“S”形弯道经过不断发育, 主流于神堤工程下首靠溜, 主流在流出神堤工程后, 在沙鱼沟工程下部北岸 的滩地折转约 $45^{\circ}$ 向北岸流去, 而后又连续折转 $90^{\circ}$ 以横河河势冲向南岸 ${ }^{[6]}$. 此时河势与规划河势相差较大, 畸形河湾形成 (图 6b). 畸形河湾在此后基本保持不变,在 2008 年汛期, 汛期最大流量超过 $3500 \mathrm{~m}^{3} / \mathrm{s}, 2007$ 年汛后所形成的串沟冲刷连通,开始发生自然裁弯, 同时水流在伊洛河口断面处分汉,河段游荡性增加 (图 6c). 而后连续几年汛期流量均较小, 裁弯新河道不断发展, 但未能完全发展成为主河道, 直至 2012 年汛期, 汛期洪峰流量超过 $4000 \mathrm{~m}^{3} / \mathrm{s}$, 裁弯彻底完成. 在 2008 年汛后, 旧河道成为牛轭湖, “ $\Omega$ ”形河湾消亡, 主流在 神堤工程靠溜,水流通过裁弯取新河道流向下游,横河河势基本消除(图 6d).
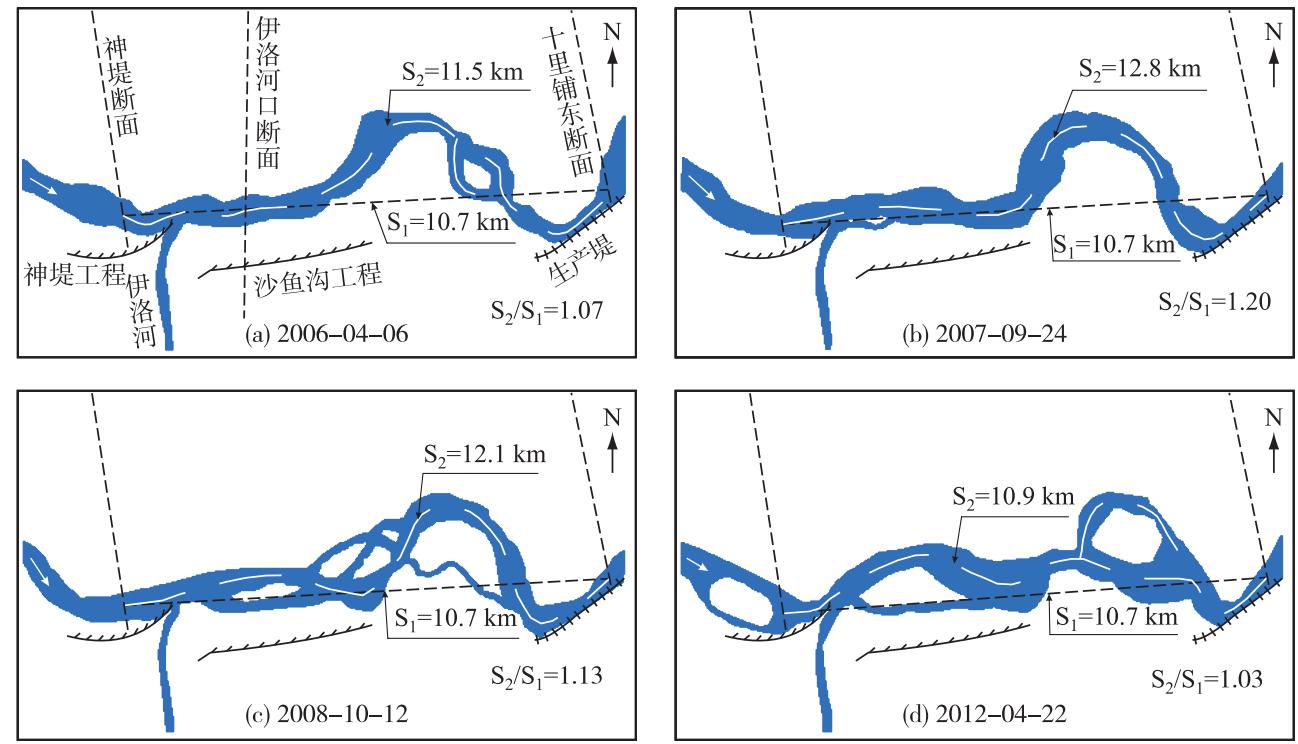

图 $62006-2012$ 年巩义神堤一英峪畸形河湾演变过程

Fig. 6 Evolution processes of an abnormal river bend of the reach between Gongyishendi and Yingyu during 2006-2012

\section{2 柳园口一古城畸形河湾的演变过程}

在 2003 年汛后,柳园口一古城河段形成两个方向相反的弯道,初步形成反“S”形河湾 (图 7a), 但水流流向 与工程布置方向基本一致,河道整治工程仍具有一定的控制作用. 据花园口水文站数据,此河段 2004 年汛期 平均流量仅有 $821.7 \mathrm{~m}^{3} / \mathrm{s}$, 河湾在小水情况下不断发育,在 2004 年汛后, 此河段已形成严重的畸形河湾 (图 $7 b)$. 此时大宫控导工程仅在工程中部部分靠河, 水流在工程中部折转近 $90^{\circ}$ 后向南岸流去, 然后在大宫工程与 王庵工程之间, 连续经过 3 个 $90^{\circ}$ 的折转后流向王庵工程下首 ${ }^{[6]}$. 在王庵工程和古城工程之间, 畸弯相连, 水流 流向复杂多变, 不仅有横向的, 还有倒向的 ${ }^{[6]}$, 且在王庵工程处形成抄后路的河势. 2005 年汛期, 汛期平均流量 较上一年略有增加, 为 $891.6 \mathrm{~m}^{3} / \mathrm{s}$, 但水流含沙量仅有 $6.73 \mathrm{~kg} / \mathrm{m}^{3}$, 较上一年减少约 $66 \%$, 在含沙量较低的水流 冲刷下, 此河段两个发育充分的畸形河湾分别发生斜槽裁弯和颈口裁弯. 但由于汛期平均流量和洪峰流量 $\left(2720 \mathrm{~m}^{3} / \mathrm{s}\right)$ 较小, 王庵工程处畸形河湾裁弯失败,水流抄后路的形势依然十分严重 (图 7c). 为防止畸形河湾 
给黄河大堤和滩区带来危险, 此河段在 2005 年 10 月 19 日对王庵工程处的畸形河湾进行切滩导流、裁弯取直, 消除畸形河湾 ${ }^{[23]}$. 在图 $6 \mathrm{c}$ 中, 人工裁弯的新河道已取代旧河道成为水流的主要通道. 在首次切滩导流成功后, 王庵工程处的险情和滩地坍塌有所改善, 但大宫工程处弯道持续向下游移动. 为防止再次形成畸形河湾, 此河 段在 2006 年 2 月 24 日再次进行切滩导流, 至 3 月 31 日, 主流进人引河, 河道东移 $500 \mathrm{~m}$ 以上 ${ }^{[23]}$. 两次人工裁 弯后, 河势逐渐改善, 在 2006 年汛期水流的冲刷下, 河势进一步改善, 畸形河湾基本消除, 大宫工程中部靠溜, 河势基本受工程控制,横河河势得到改善, 原畸形河湾裁弯后形成牛轭湖(图 7d).
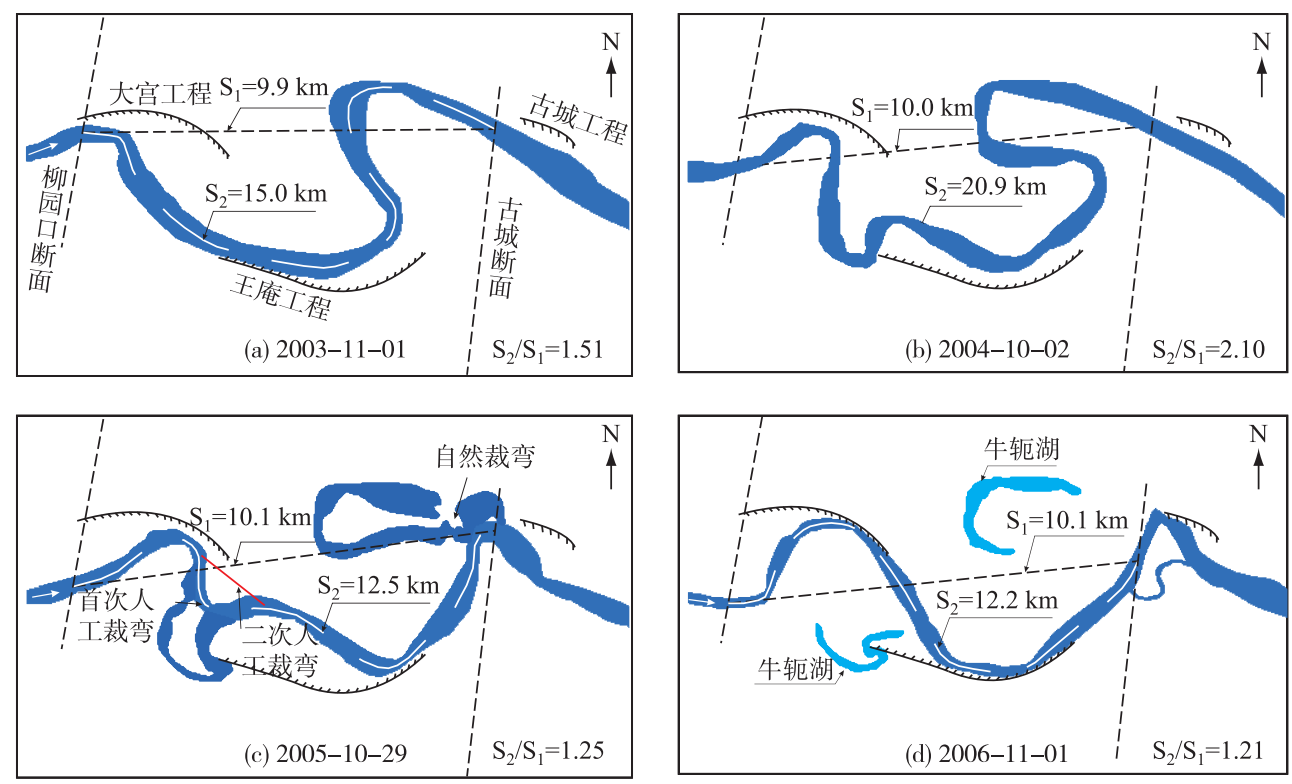

图 $72003-2006$ 年柳园口一古城畸形河湾演变过程

Fig.7 Evolution processes of an abnormal river bend of the reach between Liuyuankou and Gucheng during 2003-2006

\section{3 王夹堤一王高寨畸形河湾的演变过程}

1992 年汛后, 在汛期洪峰流量接近 $5000 \mathrm{~m}^{3} / \mathrm{s}$ 的水流冲刷下,此河段河势较稳定,水流基本按规划方向 行进, 并且受工程控制. 但由于弯道在王夹堤工程处受到限制, 无法向下移动, 在 1993 年汛后, 此河湾演变 形成明显的 “ $\Omega$ ”形畸形河湾 (图 8a). 与此同时, 被大留寺工程限制的河湾也逐渐向畸形河湾演变. 1994 年 汛期, 河段洪峰流量接近 $4500 \mathrm{~m}^{3} / \mathrm{s}$, 充分发育的“ $\Omega$ ”形畸形河湾发生斜槽裁弯, 但大留寺工程上首的河湾 仍不断发展演变, 未发生裁弯. 1995 年汛期水流较小, 洪峰流量仅为 $3130 \mathrm{~m}^{3} / \mathrm{s}$, 大留寺工程上首的河湾持续 发育并最终与“ $\Omega$ ”形畸形河湾的新旧河道相连,在汛后形成大“ $M$ ”形畸形河湾 (图 8b). 1996 年 8 月,黄河 下游降雨剧增, 在洪峰流量接近 $7000 \mathrm{~m}^{3} / \mathrm{s}$ 的大洪水的冲刷下, 原 “ $\Omega$ ”形畸形河湾旧河道彻底消亡, 新河道 成为主河道, 大留寺工程上首的“ $M$ ”形畸湾转化为 “ $\Omega$ ”形畸湾, 但其扭曲程度仍十分严重 (图 8c ). 在 1997 年汛前, 王夹堤工程下游滩地处的河湾湾顶不断向左岸移动, 并最终与旧河道相连, 对新 “ $\Omega$ ” 形畸形河湾进 行了斜槽裁弯 (图 8c). 1997 年汛期, 王高寨工程前的弯道发生斜槽裁弯, 至汛后, 此河段畸形河湾彻底消 亡. 河势进一步稳定,工程基本靠河,水流在工程控制下向下游行进 (图 8d).

\section{3 河湾形态参数和断面形态的变化}

\section{1 河湾形态参数的变化}

3.1.1 弯曲度的变化 根据不同年份的汛前或汛后遥感影像, 选出 8 幅具有代表性的遥感图像计算其弯曲度 并分析畸形河湾的演变过程,如图 9 所示. 

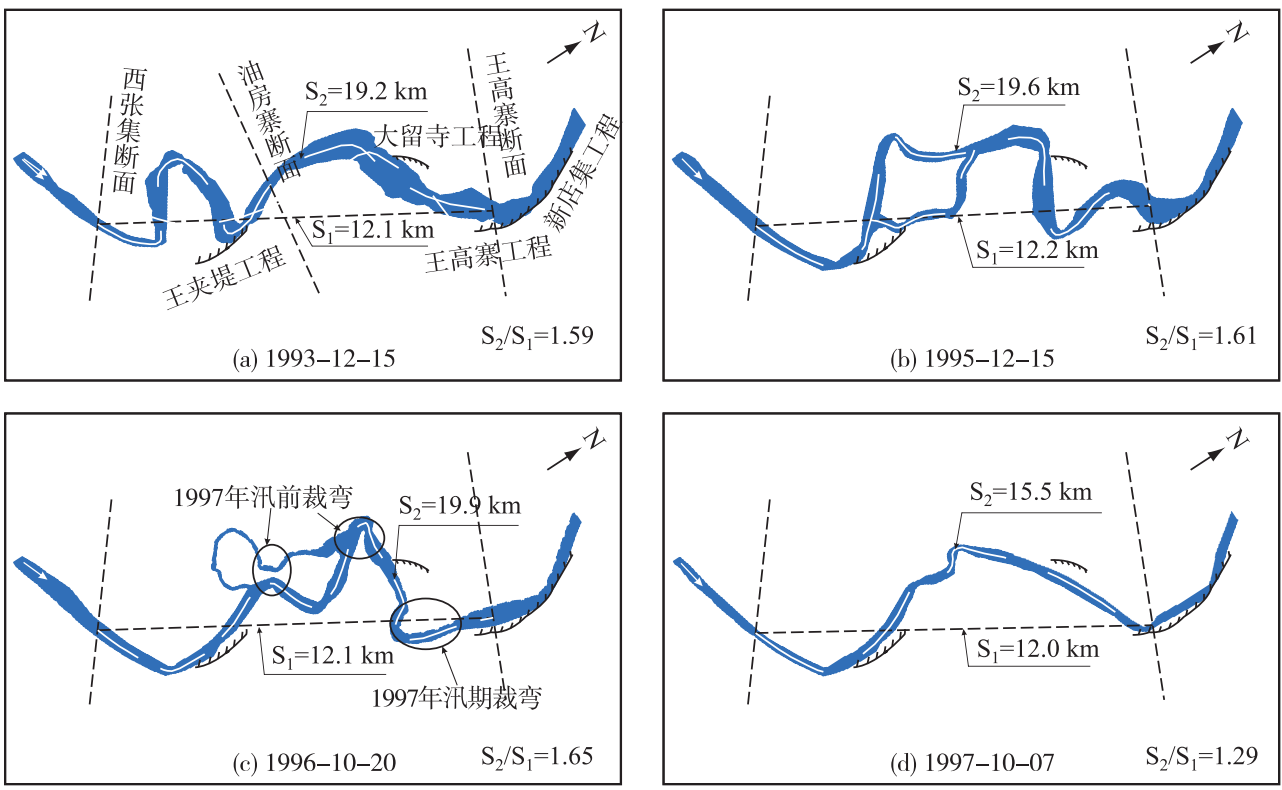

图 8 1992-1997 年王夹堤一王高寨畸形河湾演变过程

Fig. 8 Evolution processes of an abnormal river bend of the reach between Wangjiadi and Wanggaozhai during 1992-1997
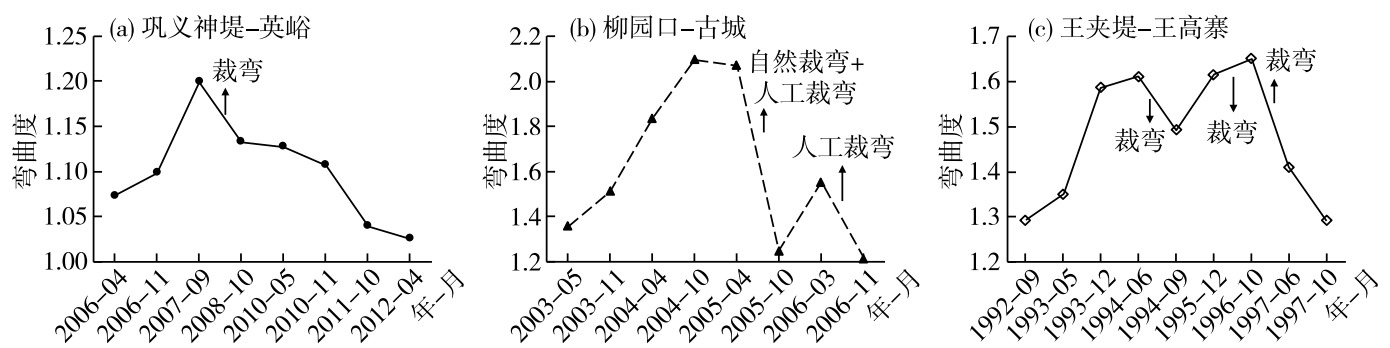

图 9 典型畸形河湾弯曲度变化

Fig.9 Temporal variation of sinuosity in typical abnormal river bends

由于两固定断面间的直线距离变化较小,而河道中心线的长度随畸形河湾的演变而不断延长, 因此弯 曲度主要受河道中心线长度的影响. 如图 9 所示, 在畸形河湾的形成阶段, 由于畸形河湾的不断发育, 弯曲 度不断增大; 当河湾发生裁弯时, 原有的蜿蜒河道逐渐被裁弯新河道取代, 弯曲度也随之大幅减小. 对于柳 园口一古城畸形河湾,2005 年汛期该河段发生自然裁弯,并且在 10 月 19 日进行人工裁弯,因此 2005 年 10 月 29 日中所获取的遥感影像中弯曲度大幅减少至 1.21 , 但随后畸形河湾继续发展, 弯曲度也随之增加, 在 2006 年 3 月二次人工裁弯成功后, 弯曲度的增加被遏止, 至 2006 年汛后, 弯曲度减小至 1.20 , 与未形成畸形 河湾前大小相近. 在图 9c 中, 弯曲度出现了两个峰值, 很好地反映了王夹堤一王高寨河段接连形成了“ $\Omega$ ”形 和 “ M” 形 2 个畸形河湾的情况. 巩义神堤一英峪、柳园口一古城和王夹堤一王高寨 3 个畸形河湾的弯曲度的 最大值分别为: $1.21 、 2.10$ 和 1.61 , 反映了 3 个河湾的扭曲程度, 即柳园口一古城河段的畸形河湾最为扭曲, 弯曲度也最大; 巩义神堤一英峪河段的畸形河湾扭曲程度较小, 弯曲度最小.

3.1 .2 平面形态参数的变化 此处选取王夹堤一王高寨畸形河湾为研究对象, 分析曲率半径 $R$ 、水流夹角 $a$ 、 河湾振幅 $P$ 和河湾间距 $T$ 在畸形河湾演变过程中的变化. 由于王夹堤河段同时形成了 “ $\Omega$ ”形和 “ $\mathrm{M}$ ”形畸形 
河湾, 因此分别讨论两个畸形河湾的形态参数的变化过程. 下载 1993-1997 年该河段每年汛前和汛后该河 段的遥感影像并计算其河湾形态参数,结果如图 10 和图 11 所示.

图 10a 反映了“ $\Omega$ ” 形畸形河湾演变过程中河湾曲率半径和水流夹角的变化. 1992 年汛后此河段并未形 成畸形河湾, 但在 1993 年汛前此河段的河湾迅速发展, 形成曲率半径为 $626 \mathrm{~m}$ 的畸形河湾, 此河湾在汛期未 发生裁弯并继续发育, 至 1994 年汛前, 河湾的曲率半径减小至 $422 \mathrm{~m}$, 河湾扭曲程度加剧. 在 1994 年汛期大 水作用下, 此 “ $\Omega$ ”形畸形河湾发生颈口裁弯, 裁弯后河道接近直线, 曲率半径急剧增大至 $2500 \mathrm{~m}$ 以上, 为最 小曲率半径的 $605 \%$. 随着曲率半径的减小, 水流夹角逐渐增大, 至 1993 年 12 月, 水流夹角最大达 $157^{\circ}$, 对 两岸滩地和导流工程的顶冲作用也越来越强. 但与曲率半径不同, 水流夹角在裁弯开始前已开始减小至 $133^{\circ}$, 在裁弯的作用下, 水流夹角进一步减小, 至 1994 年汛后已减小至 $92^{\circ}$, 为最大水流夹角的 $59 \%$. 图 10b 反映了 “ $\Omega$ ”形畸形河湾演变过程中河湾间距和河湾振幅的变化. 与曲率半径变化趋势相反, 河湾振幅在 “ $\Omega$ ”形畸形河湾演变过程中逐渐增加, 在裁弯前已从畸形河湾形成初期的 $1238 \mathrm{~m}$ 增大至 $2548 \mathrm{~m}$, 在一年时 间内增加了 $106 \%$, 在河湾裁弯后, 河湾振幅大幅减小至 $693 \mathrm{~m}$, 约为最大河湾振幅的 $27 \%$. 河湾间距的变化 趋势与河湾振幅呈相反趋势, 但与河湾振幅不同, 河湾间距在 1993 年汛后已减小至最小值 $2204 \mathrm{~m}$, 在 1994 年汛期裁弯开始前河湾间距已开始增大, 在裁弯后进一步增大至 $2921 \mathrm{~m}$, 为最小河湾间距的 $133 \%$. 由图 $10 \mathrm{~b}$ 可以看出, 相对于河湾振幅, 河湾间距畸形河湾的演变过程中, 变化速率较小.
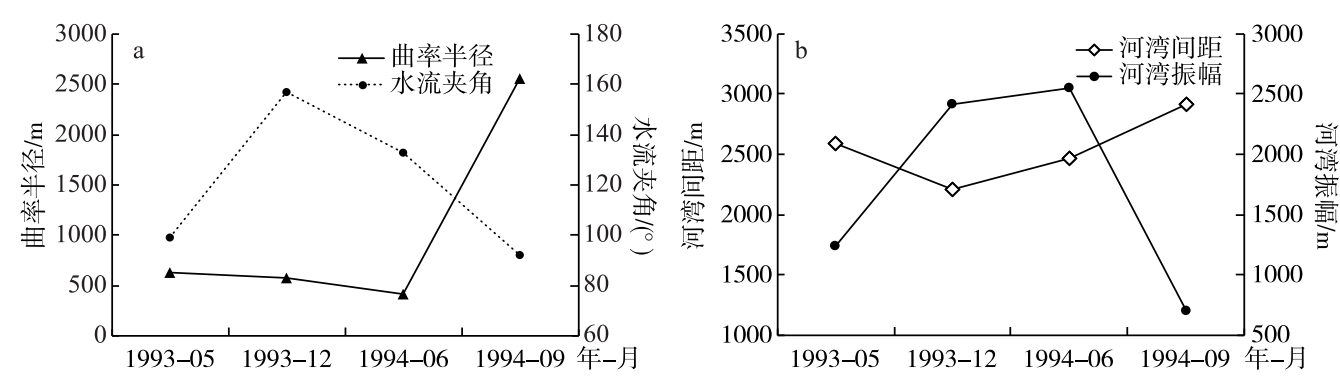

图 10 王夹堤一王高寨“ $\Omega$ ”形畸形河湾形态参数变化

Fig.10 Temporal variations in the morphological parameters of a $\Omega$-shaped abnormal river bend of the reach between Wangjiadi and Wanggaozhai

“ $\Omega$ ”形畸形河湾消亡后, “ M”形畸形河湾开始发育, 在 1995 年汛后已形成明显的“ $M$ ”形畸形河湾 (图 $8 \mathrm{c}$ ), 并在 1996 年汛期开始发生裁弯. 对于 “ M” 形畸形河湾, 此处仅研究水流夹角、河湾间距和河湾振幅的 变化 (图 11). 1995 年汛前, 原“ $\Omega$ ”形畸湾旧河道与其下游的河湾相连形成 “ $M$ ” 形畸形河湾, 因此在 “ $M$ ”形 畸湾形成初期, 水流夹角较大, 达 $158^{\circ}$. 水流对两岸滩地顶冲作用大, 形成明显的横河河势 (图 8c). 经过一 个汛期, 水流夹角有小幅升高, 但随后水流夹角持续下降, 至 1997 年汛后水流夹角减小至 $58^{\circ}$, 约为最大水 流夹角的 $37 \%$. 裁弯后水流通过微弯河道流向下游, 水流夹角减小, 对两岸滩地顶冲作用减弱. 图 $10 \mathrm{~b}$ 给出 了“M”形畸形河湾演变过程中河湾间距和河湾振幅的变化, 与 “ $\Omega$ ”形畸湾相比, “ M” 形畸湾的河湾振幅和 河湾间距均较大. 在裁弯前, 河湾振幅持续增加, 至裁弯前的 1996 年 6 月河湾振幅为 $3.8 \mathrm{~km}$, 年增加超过 1 km. 1996 年汛期裁弯后, 河湾振幅持续减小至 $3.2 \mathrm{~m}$, 约为最大振幅的 $83 \%$, 但下降速率较小, 约为 $0.6 \mathrm{~km} / \mathrm{a}$. 河湾间距的变化趋势整体与河湾振幅相反. 在畸形河湾形成初期, 河湾间距达 $8.5 \mathrm{~km}$, 至 1995 年汛后减少 了约 $2.5 \mathrm{~km}$. 在 1996 年汛期裁弯前河湾间距开始逐渐增大, 且增长速率较快, 约为 $2 \mathrm{~km} / \mathrm{a}$, 裁弯后河湾间距 进一步增大,至 1997 年增大至 $9.8 \mathrm{~km}$,约为最小河湾间距的 $152 \%$.

综上所述, 当裁弯后水流通过微弯河道流向下游, 且形成稳定河势时, “ $\Omega$ ” 形畸形河湾的曲率半径、水 流夹角、河湾振幅和河湾间距约为其形成“ $\Omega$ ”形畸形河湾时最值的 $605 \% 、 59 \% 、 27 \%$ 和 $133 \%$. 对于“ $M$ ”形畸 形河湾, 裁弯后水流夹角、河湾振幅和河湾间距约为其最值的 $37 \% 、 83 \%$ 和 $152 \%$. 可以看出, 畸形河湾的形 成是一个曲率半径和河湾间距减小, 水流夹角和河湾振幅增大的过程. 对于 “ $\Omega$ ”形畸湾, 曲率半径和河湾振 幅在演变过程中变化明显, 而“ $M$ ”形畸湾则是水流夹角和河湾跨度变化明显. 

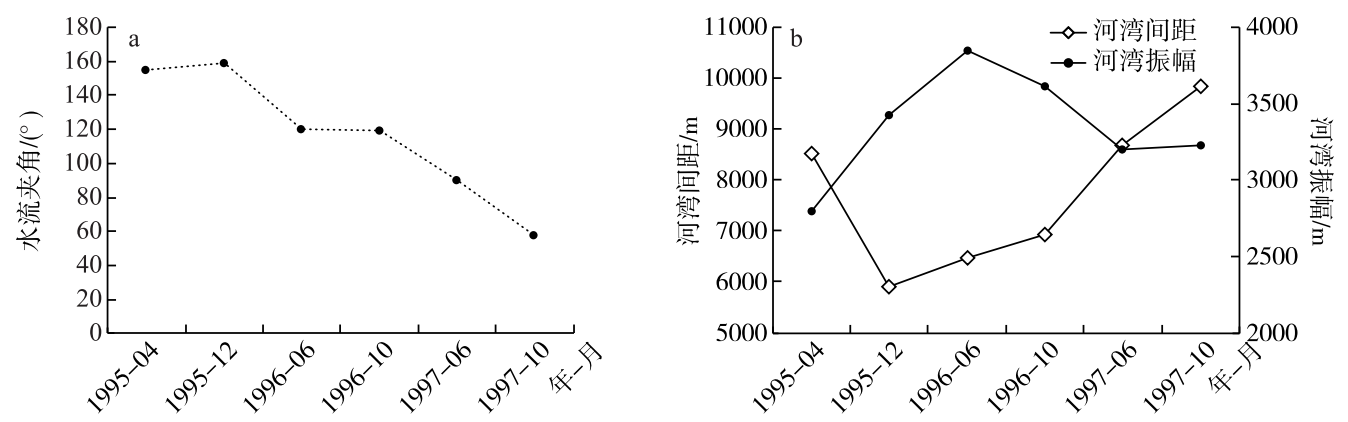

图 11 王夹堤一王高寨“ M”形畸形河湾形态参数变化

Fig.11 Temporal variations in the morphological parameters of a M-shaped abnormal river bend of the reach between Wangjiadi and Wanggaozhai

\section{2 断面形态的变化}

畸形河湾一般是局部性的, 影响的河段长度一般在 $20 \mathrm{~km}$ 以内. 因此特定断面的形态变化可以反映出 该河段断面形态的变化. 图 12 为 2006-2008、2012 年伊洛河口断面的汛后实测横断面套汇图,该断面位于 神堤一英峪畸形河湾斜槽裁弯上游, 其相对位置如图 6 所示.

在巩义神堤一英峪畸形河湾的演变过程中, 2006-2007 年是畸形河湾的形成时期,而 2008-2012 年是 畸形河湾的裁弯时期. 由图 12 可知: 在畸形河湾形成时期,随着畸形河湾湾顶不断向左岸 (凹岸) 滩地移动, 其上游河道也逐渐向左岸拓宽, 速率为 $94 \mathrm{~m} / \mathrm{a}$, 而右岸 (凸岸) 河床在此期间基本保持不变. 由于下游畸形 河湾的存在, 水流输沙能力下降, 泥沙淤积在畸形河湾上游, 致使伊洛河口断面抬升, 深泓点位置上移约 1 m. 根据花园口水文站的资料, 2006-2008、2012 年的汛期洪峰流量分别为 $2340 、 3760 、 3660$ 和 $4150 \mathrm{~m}^{3} / \mathrm{s}$. 2006-2008 年, 汛期洪峰流量较小, 水流几乎不漫滩, 深槽左岸的嫩滩的畸形河湾形成时期变化不大, 而后 随着裁弯的不断冲刷, 左岸滩地崩退, 但仍有相当大一部分的滩地在此期间没有发生变化. 2008-2012 年, 在畸湾裁弯过程中, 位于斜槽裁弯上游侧的伊洛河口不断发展冲刷, 河槽两侧滩地不断崩塌, 河槽拓宽. 其 中, 左岸移动速率为 $134 \mathrm{~m} / \mathrm{a}$, 右岸移动速率较小, 为 $16.75 \mathrm{~m} / \mathrm{a}$. 同时, 随着裁弯的不断发展, 部分水沙从新 河道向下游流去, 河道输沙能力增强, 且河道在伊洛河口断面处逐渐发展为分汉河流, 断面上出现两个深泓 点并不断下切, 较 2007 年最大下切 $2 \mathrm{~m}$. 对比 2008 年和 2012 年的断面形态图可以看出, 裁弯发展时冲刷首 先从深泓点开始, 裁弯开始时深泓点快速下切, 而随着裁弯的不断发展, 冲刷从深泓点逐渐向两边发展, 最 终深泓点附近河床的高程与深泓点基本一致. 至 2012 年裁弯完成, 深槽宽度为畸湾形成时宽度的 2.2 倍, 断 面面积增大, 河道过水输沙能力大大提升.

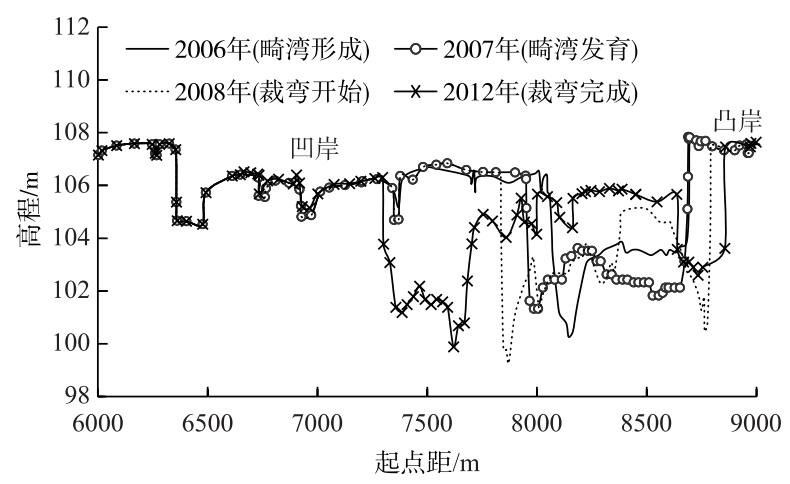

图 12 2006-2012 年伊洛河口断面形态的变化

Fig.12 Temporal variation in the cross-sectional profile at the Yiluo River outlet during 2006-2012 


\section{4 结论}

1) 相较于弯曲河流的河湾, 黄河下游游荡段畸形河湾的演变时间较短,一般为 $2 \sim 8$ 年, 并且不断向两岸 滩地延伸, 河湾扭曲程度大, 易在流量较大的汛期发生裁弯. 但由于游荡段主流摆动频繁, 汛后主流可能回 归旧河槽, 导致裁弯失败, 畸湾继续发展. 游荡段 3 个典型畸形河湾的演变特点相差较大, 其中游荡段上段 的畸形河湾演变缓慢, 裁弯过程长; 中段的畸形河湾演变快速, 河湾扭曲程度大; 下段的畸形河湾演变迅速, 容易发生自然裁弯.

2) 在畸形河湾的演变周期内, 弯曲度逐渐增加,裁弯完成后则迅速减小至畸形河湾形成前的大小. 河湾 越扭曲, 弯曲度越大, 同时也越容易发生自然裁弯. 游荡段 3 个畸形河湾弯曲度的最大值分别为 $1.20 、 2.10$ 和 1.61 , 反映了不同畸形河湾的扭曲程度. “ $\Omega$ ” 形畸形河湾裁弯后的曲率半径、水流夹角、河湾振幅和河湾 间距约为其演变过程中最值的 605\%、59\%、27\% 和 133\%. 对于 “M”形畸形河湾,裁弯后水流夹角、河湾振幅 和河湾间距约为其最值的 $37 \%$ 、83\% 和 $152 \%$. 所以畸形河湾的形成是一个曲率半径和河湾间距减小, 水流 夹角和河湾振幅增大的过程. 在畸形河湾形成时期, 伊洛河口断面位于畸形河湾凹岸侧的滩地不断崩塌, 速 率约为 $94 \mathrm{~m} / \mathrm{a}$. 在裁弯后, 河槽遭受冲刷, 两岸滩地崩退, 河槽展宽速率为 $148 \mathrm{~m} / \mathrm{a}$, 而河床底部的冲刷主要 从深泓点逐渐向两边发展, 最终深泓点附近河床的高程与深泓点基本一致.

\section{5 参考文献}

[ 1 ] Chen JG, Deng AJ, Dai Q et al. Hydrological background of channel shrinkage in the Lower Yellow River. Journal of Sediment Research, 2003, (4) : 1-7. [陈建国, 邓安军, 戴清等. 黄河下游河道萎缩的特点及其水文学背景. 泥沙研究, $2003,(4): 1-7$.

[ 2 ] Xu JX, Sun J. Tendency of channel change of the lower yellow river during its shrinkage. Journal of Sediment Research, 2003, (1) : 10-17. [许昫心, 孙季. 黄河下游游荡河道萎缩过程中的河床演变趋势. 泥沙研究, 2003, (1) : 10-17.]

[ 3 ] Xu JX. Fill-scour thresholds of lower huanghe river influenced by channel shrinkage. Scientia Geographica Sinica, 2010, (3) : 403-408. [许昫心. 黄河下游河道萎缩对冲淤临界的影响. 地理科学, 2010, (3) : 403-408.]

[ 4 ] Xu JX, Lu ZC, Liu JX. Formative cause of distorted bends in the braided Lower Yellow River in the process of channel shrinkage. Journal of Sediment Research, 2000, 1(3) : 36-41. [许畑心, 陆中臣, 刘继祥. 黄河下游河床萎缩过程中 畸形河湾的形成机理. 泥沙研究, 2000, 1(3) : 36-41.]

[ 5 ] Frascati A, Lanzoni S. Long-term river meandering as a part of chaotic dynamics? A contribution from mathematical modelling. Earth Surface Processes and Landforms, 2010, 35(7) : 791-802.

[6] Hu YS. Deformed river bend of regime evolution in the lower Yellow River. Yellow River, 2016, 38: 43-48. [胡一三. 黄 河下游河势演变中的畸形河湾. 人民黄河, 2016, 38: 43-48.]

[ 7 ] Niu YG, Duanmu LM, Zhou NB. Causes of irregular channel regime and countermeasures in the Lower Yellow River. Yellow River, 2013, 35: 1-2, 9. [牛玉国, 端木礼明, 周念斌. 黄河下游畸形河势成因及治理对策. 人民黄河, 2013, 35: 1-2, 9.]

[ 8 ] Sun ZY, Ye CS, Qu SJ. Influence of irregular channel regime to the flood discharge capability of channel and countermeasures. Yellow River, 2007, 29: 13-14. [孙赞盈, 叶春生, 曲少军. 畸形河势对河道排洪能力的影响及对策. 人民黄 河, 2007, 29: 13-14.]

[ 9 ] Zhang LZ, Dong QH, Wang Q. Study on the evolutional law and the river training measures of the freakish river regime in the Lower Yellow River. Yellow River, 2015, 37: 32-35. [张林忠, 董其华, 万强. 黄河下游畸形河势演化规律及其整 治措施. 人民黄河, 2015, 37: 32-35.]

[10] Li ZW, Wang ZY, Zhao N et al. Development process of chute cutoff on meandering Rivers. Advances in Water Science, 2013, 24(2) : 161-168. [李志威, 王兆印, 赵娜等. 弯曲河流斜槽裁弯模式与发育过程. 水科学进展, 2013, 24 (2) : 161-168.]

[11] Li ZW, Yu GA, Brierley G et al. Migration and cutoff of meanders in the hyperarid environment of the middle Tarim River, northwestern China. Geomorphology, 2017, 276: 116-124. 
[12] Jiang EH, Cao YT, Zhang LZ et al eds. Study on the evolution law and mechanism of river regime in the braided reach of the Lower Yellow River. Beijing: China Water Power Press, 2006. [江恩惠, 曹永涛, 张林忠等. 黄河下游游荡性河段 河势演变规律及机理研究. 北京: 中国水利水电出版社, 2006. ]

[13] Qian N, Zhou WH eds. Channel evolution in the Lower Yellow River. Beijing: Science Press, 1965. [钱宁, 周文浩. 黄 河下游河床演变. 北京:科学出版社, 1965.]

[14] Hu YS. Variation of river regime of the Yellow River. Shuili Xuebao, 2003, 4: 46-50, 57. [胡一三. 黄河河势演变. 水 利学报, 2003, 4: 46-50, 57.]

[15] Xu G, Si C. Effect of water and sediment regulation on lower Yellow River. Transactions of Tianjin University, 2009,15 : 113-120.

[16] Kang Q, Wang XL. Application of remote sensing technology in riverbed changes. Acta Scientiarum Naturalium Universitatis Sunyatseni, 1999, 38(5) : 109-113. [妄庆, 王兴玲. 河道演变的遥感研究方法及应用. 中山大学学报: 自然科学版, 1999, 38(5): 109-113.]

[17] Fischer WA, Hemphill WR, Kover A. Progress in remote sensing (1972-1976). Photogrammetria, 1976, 32(2): 33-72.

[18] Kerr JT, Ostrovsky M. From space to species: ecological applications for remote sensing. Trends in Ecology \& Evolution, 2003, 18(6) : 299-30.

[19] Chao Y, Cai X, Wang X. Remotely sensed trajectory analysis of channel migration in Lower Jingjiang Reach during the period of 1983-2013. Remote Sensing, 2015, 7: 16241-16256.

[20] Campbell JB, Wynne RH eds. Introduction to remote sensing. New York: Guilford Press, 2011.

[21] Wang YZ, Xia JQ, Zhou MR et al. Characteristics of main channel migration in the braided reach of the Lower Yellow River after the Xiaolangdi Reservoir operation. Advances in Water Science, 2019, 30(2) : 198-209. [王英珍, 夏军强, 周美 蓉, 等. 小浪底水库运用后黄河下游游荡段主槽摆动特点. 水科学进展, 2019, 30(2): 198-209.]

[22］Xie JH ed. River bed evolution and regulation. Wuhan: Wuhan University Press, 2013. [谢鉴衡. 河床演变及整治. 武 汉:武汉大学出版社, 2013.]

[23] Zhang LZ, Jiang EH, Cao YT. Analysis on the shape of irregular river bend and the feasibility of bend cut-off in the Lower Yellow River. Yellow River, 2013, 35(9) : 41-42. [张林忠, 江恩惠, 曹永涛. 黄河下游畸形河湾形态及裁弯的可行 性分析. 人民黄河, 2013, 35(9) : 41-42.] 